\title{
Chapter 34 \\ Paths Forward for Evaluating Seismic Performance of Geotechnical Structures
}

\author{
Susumu Iai
}

\begin{abstract}
Two suggestions are provided for expanding the scope of LEAP project for the next stage. The first suggestion is to perform undrained cyclic shear tests with addditional static deviator stress to represent more realistic stress conditions in soilstructure systems during earthquakes. The other suggestion is to perform centrifuge model tests with non-homogeneous soil layer such as mildly sloping ground of liquefiable sand overlain by a less permeable capping crust layer, leading to a unlimited flow failure of surface crust. Effects of void ratio redistribution and seepage flow will be studied in detail in this type of cetrifuge tests.
\end{abstract}

\subsection{Thesis Statement}

The paths forward for evaluating seismic performance of geotechnical structures along the framework of LEAP project are to expand the scope of soil element tests from the conventional cyclic undrained tests toward the undrained shear with additional static deviator stress and to expand the scope of centrifuge tests from the behavior of homogenous sand deposit toward the non-homogenous sand deposit involving the effects of void redistribution due to pore water flow.

\subsection{Essay}

The laboratory tests of soil specimens have been typically performed through drained/undrained monotonic and cyclic shear tests. However, soil element behavior in the typical soil-structure system in two or three dimension includes the effect of initial static deviator stress in addition to the cyclic shear during shaking. The paths forward to improving the understanding of the source of uncertainty in evaluating

\footnotetext{
S. Iai $(\triangle)$

FLIP Consortium, Kyoto, Japan

e-mail: iai.susumu@flip.or.jp

(C) The Author(s) 2020

B. Kutter et al. (eds.), Model Tests and Numerical Simulations of Liquefaction

and Lateral Spreading, https://doi.org/10.1007/978-3-030-22818-7_34
} 


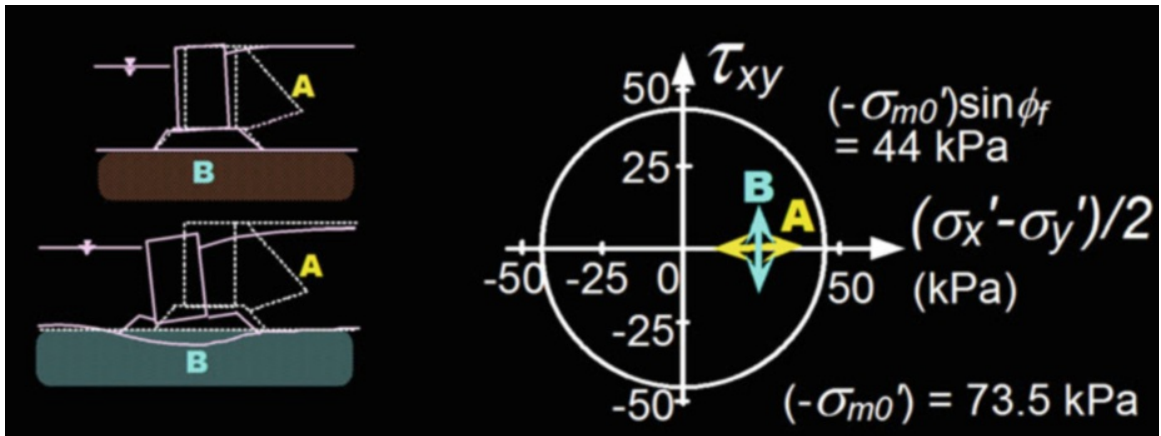

Fig. 34.1 Laboratory soil element tests with combination of static and cyclic undrained shear

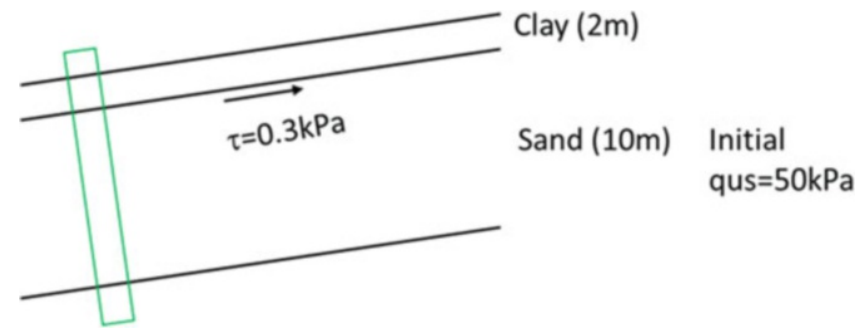

Fig. 34.2 Centrifuge tests of mildly sloping ground of liquefiable sand deposit overlain by surface crust layer of less permeable nature

the seismic behavior of soil-structure systems are to include this type of soil element tests. Figure 34.1 indicates two of the possible combinations of the static and cyclic shear.

The stress path $\mathrm{A}$ is easier to perform using the triaxial testing device. The stress path $\mathrm{B}$ is more difficult to perform and needs a testing device such as a hollow cylinder testing device. However, the stress path B has wider applications such as for evaluating behavior of shallow foundations.

The centrifuge tests of soil-structure systems have been often performed using homogenous sand deposit. In these tests, the excess pore water pressure in the sand deposit typically shows initial increase during shaking and then dissipation afterwards associated with settlement. The paths forward along the line of the LEAP project are to expand the scope toward the non-homogenous sand deposit involving the effects of void redistribution due to pore water flow.

The simplest example of the non-homogenous sand deposit can be a combination of liquefiable sand layer overlain by a surface crust layer of less permeable nature as shown in Fig. 34.2 (Iai 2017). With the slight inclination, there may be a potential for unlimited sliding along the boundary of the two layers depending on the void ratio and thus the phenomenon involved in this type of tests can be the basis for evaluating 


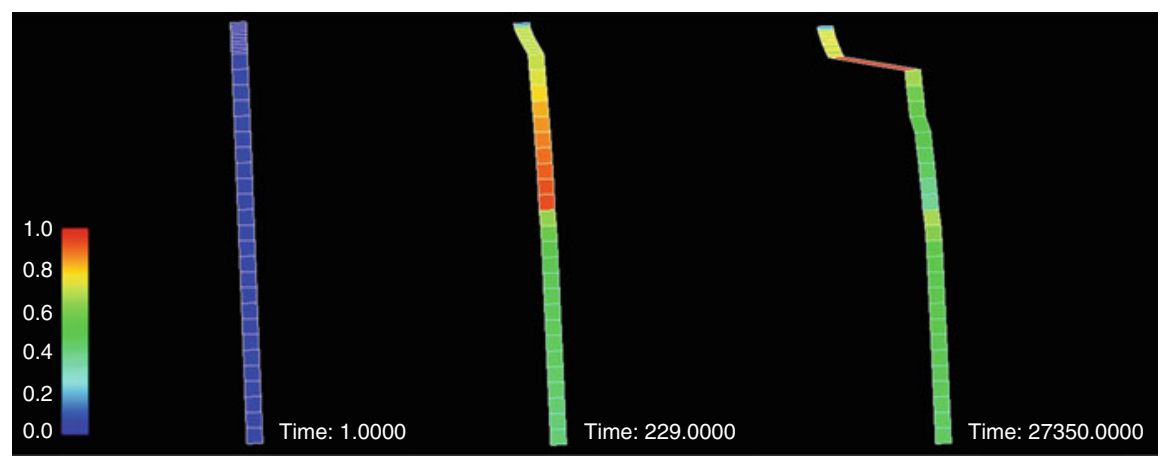

Fig. 34.3 Expected examples of numerical analysis

the combined effects of steady state, void ratio dependency, and rate of void redistribution associated with the seepage flow of pore water toward the boundary of two layers. The application of this degree of complexity in practice can be proven to be useful (Fig. 34.3).

\section{Reference}

Iai, S. (2017). Performance of port structures during earthquakes. In Proceedings of the Third International Conference on Performance-Based Design of Geotechnical Structures, Vancouver.

Open Access This chapter is licensed under the terms of the Creative Commons Attribution 4.0 International License (http://creativecommons.org/licenses/by/4.0/), which permits use, sharing, adaptation, distribution and reproduction in any medium or format, as long as you give appropriate credit to the original author(s) and the source, provide a link to the Creative Commons license and indicate if changes were made.

The images or other third party material in this chapter are included in the chapter's Creative Commons license, unless indicated otherwise in a credit line to the material. If material is not included in the chapter's Creative Commons license and your intended use is not permitted by statutory regulation or exceeds the permitted use, you will need to obtain permission directly from the copyright holder.

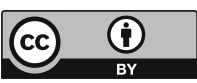

